\title{
Spatial relationships between natural resources and land use dynamics in the amazonian agricultural frontier
}

\author{
Reinis Osis \\ UMR ESO/CNPq \\ Le Mans, France \\ reinis.osis.etu@univ-lemans.fr \\ François Laurent \\ UMR ESO \\ Le Mans, France \\ francois.laurent@univ-lemans.fr
}

\author{
René Poccard-Chapuis \\ Cirad UMR SELMET \\ Montpellier, France \\ rene.poccard-chapuis@cirad.fr
}

\begin{abstract}
The objective of this work was to analyze the relationship between the natural resources (soil, topography and hydrography) and the land use dynamics in an area in eastern Amazonia between 2004 and 2013. The spatial variables used were soil texture, topographic wetness index, slope and drainage distance. We used the method of weights of evidence to observe the relations between the transitions of land use and the spatial variables. In mechanized agriculture and large landholding area, the results show that the behavior of deforestation and pasture transformation responds to the soil texture and topography variables. In the smallholding areas, the relationship with natural resources is different and may be more related to the historical development of the expansion of the valleys towards the plateaux.
\end{abstract}

Keywords - Land use change; Natural resources; Agricultural transition.

\section{INTRODUCTION}

The Brazilian Amazonia has presented an intense land use change in the last decades. Up to 2004 , about $17 \%$ of this biome had been deforested [1]. The deforestation, initially induced by land occupation incentive programs and later by non-controlled cattle ranching and mechanized agriculture expansion [2], [3] was reduced by $71 \%$ between 2004 and 2016 [1]. This reduction was due to environmental control actions, the engagement of soybean and meat production chains, credit restriction and the expansion of protected areas [4].

In this sense, agricultural producers in the Amazon are in a new context where land expansion is limited and new paths must be taken for the development as intensification and diversification of production [5]. Natural resources (such as soil, hydrography and topography) participate in this dynamic as a context in which producers make their decisions. These natural resources may have different weights in the decisions making process depending on the place and the time in which they are considered. As an example, soil fertility may be a significant factor in locating annual crops such as soybean [6], [7]. In a context of seeking a more efficient use of existing natural resources, it becomes necessary to know how farmers take these resources into account in their decisions and how their decisions change the landscape. In this sense, the present work analyzes the relationship between the land use change and natural resources/constraints in the context of an Amazonian consolidated agricultural frontier between 2004 and 2013. It was considered as an initial hypothesis that natural resources play a significant role in the dynamics of land use in the study area, as discussed by [7].

\section{METHODS}

\section{A. Study area}

The study area comprised the county of Paragominas $\left(19,340 \mathrm{~km}^{2}\right)$, in the state of Pará, northern Brazil (Fig. 1).

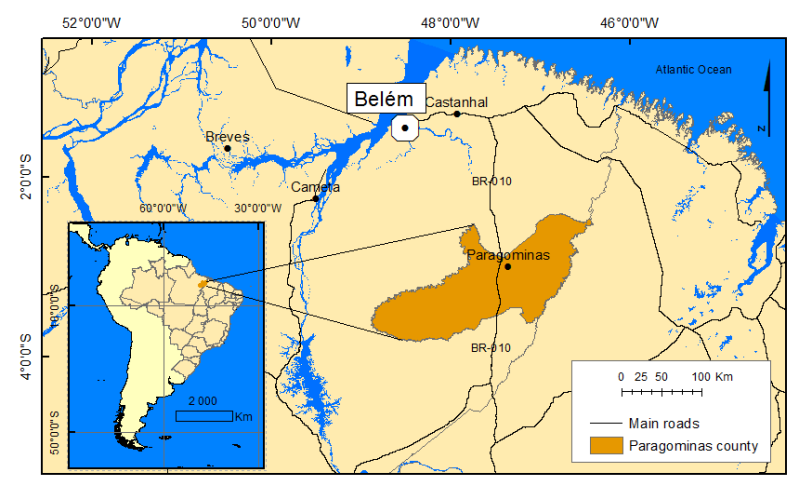

Fig. 1. Study area.

Is in Amazonian biome and receives approximately 2,000 $\mathrm{mm}$ of annual rainfall [8]. The relief is marked by dissected 
plateaux with elevations ranging from 110 and $220 \mathrm{~m}$ a.s.1., separated by wide valleys. The plateaux are characterized by the presence of clay soil and stream scarcity, while the valleys have sand soil and higher stream density.

\section{B. Data and methods}

Data from the MODIS sensor was used to establish the main land use classes for the years 2004, 2007, 2010 and 2013 [9]: mechanized agriculture, forest and pasture. It should be noted that the forest class encompasses both primary and secondary forest, and the pasture class may encompass plots of family agriculture with mixed land use (cassava, pasture, fruit trees, etc. Soil texture data [10] were used, and the topographic wetness index (TWI - spatializes the probability of occurrence of saturated soils) [11] and slope was obtained from the TOPODATA elevation model [12].

For the relationship between the land use transitions and the variables, we used the method of weights of evidence (WofE) [13] processed with the DINAMICA EGO modeling platform [14]. The WofE method consists of a Bayesian statistical procedure in which the effect of each spatial variable on each land use transition is calculated independently [14]. For each class of spatial variable, a positive weight $(\mathrm{W}+)$ can be assigned for a given transition, which means that there is a concentration of transitions in this class. A weight close to zero, in turn means that there are both transitions inside and outside this class, and a negative weight (W-) means that there is a low concentration of this transition in this class. In general, $\mathrm{W}+$ values between 0 and 0.5 are poorly predictive of a transition, between 0.5 and 1 are moderately predictive, between 1 and 2 are strongly predictive and above 2 are highly predictive [15].

Considering the differences in the dynamics of land use as a function of socioeconomic context, the weights of natural resources for land use transitions were analyzed for two distinct areas in the county of Paragominas: an area with a concentration of mechanized agriculture and extensive livestock farming (Fig. 2) in large farms and small landholding areas (Fig. 3).

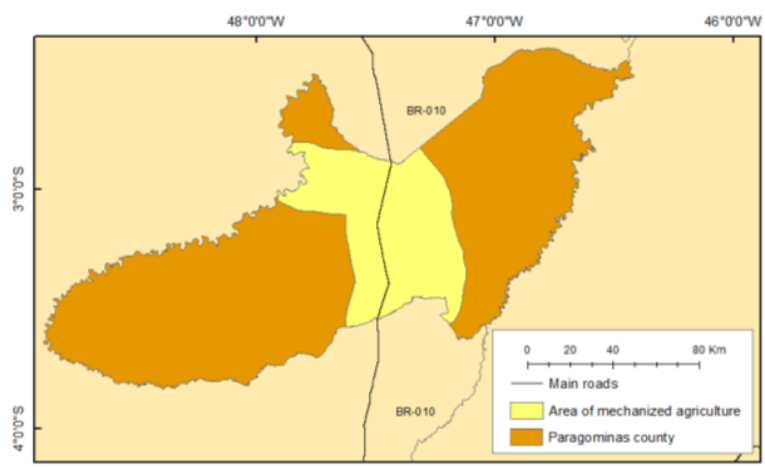

Fig. 2. Area of mechanized agriculture.

Three types of transitions were analyzed: forest-pasture, forest-pasture/family agriculture, pasture-forest and pasturemechanized agriculture.

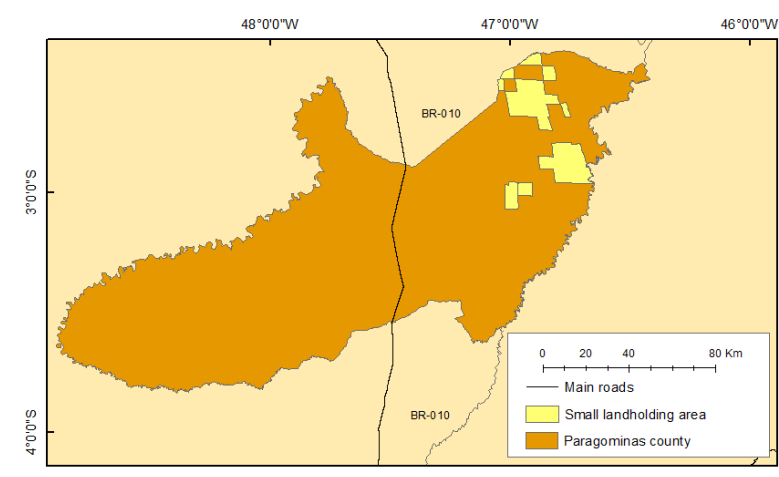

Fig. 3. Small landholding areas.

\section{RESULTS}

\section{A. Area of mechanized agriculture}

Regarding forest-pasture transition in the mechanized agriculture area, the variable that presented the strongest relation was soil texture. The sand soil class showed increasing positive weights 0.63 in 2004-2017, 0.85 in 2007 2010 and 0.86 in 2010-2013 (Fig. 4).

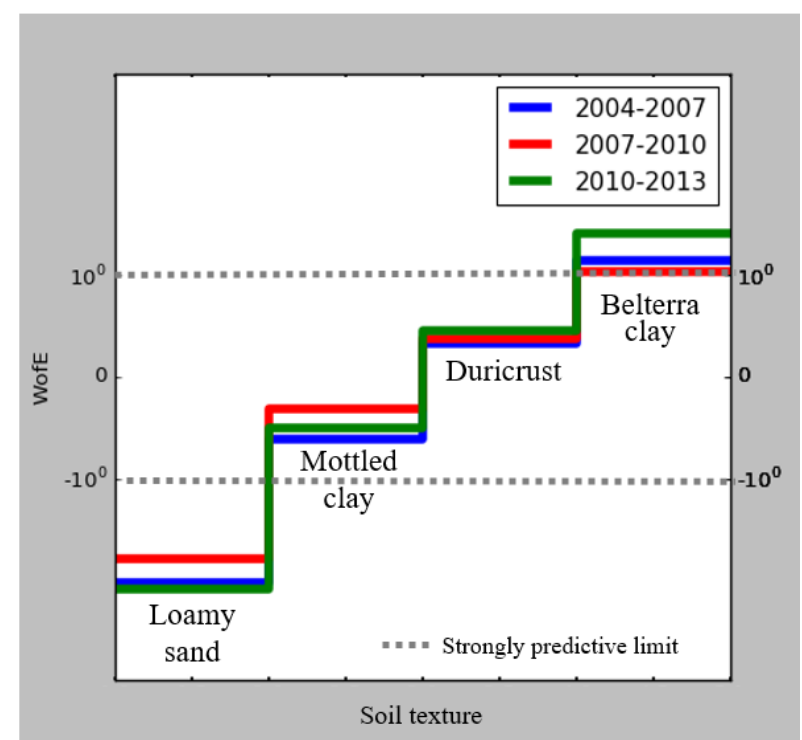

Fig. 4. Soil texture weights on pasture-agriculture transition in mechanized agriculture area.

For forest regeneration, a relationship with the TWI variable was observed. For TWI values from 0 to 5 , the values are increasing with 0.54 obtained in 2004-2007, 0.95 in 20072010 and 0.99 in 2010-2013.

In the pasture-agriculture transition, the main natural resource evidenced by the weights was also the soil texture. The clayey soils presented values 1.14 in 2004-2007, 1.04 in 2007-2010 and 1.41 in 2010-2013.

\section{B. Small landholding area}

In the small landholding area, the variable soil texture was related especially to the transition from forest to 
pasture/family agriculture. Mottled clay class presented decreasing values of 0.46 in 2004-2007, 0.39 in 2007-2010 and 0.28 in 2010-2013. However, Belterra clay weight increased between 2004 and 2013 (Fig. 5).

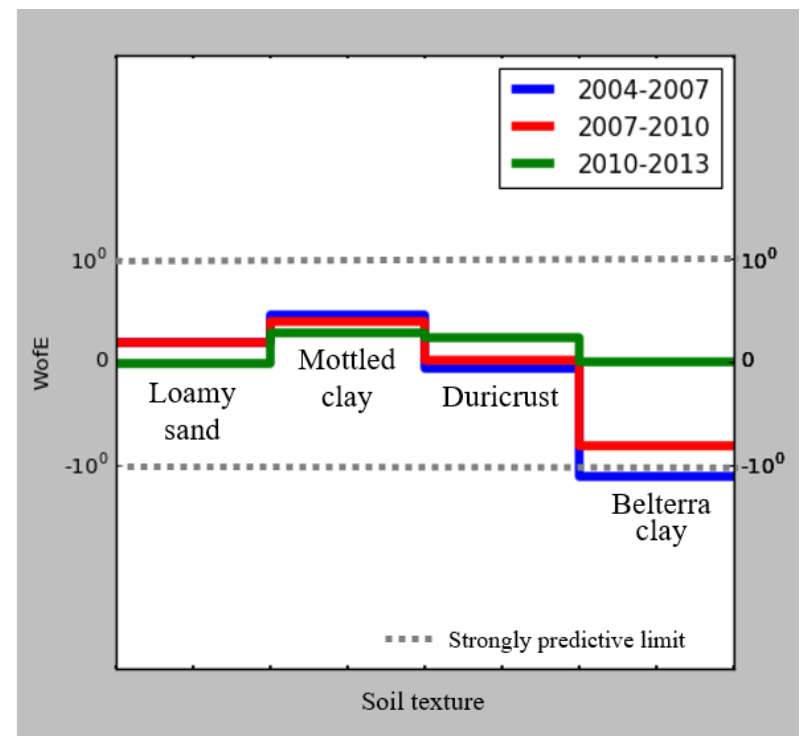

Fig. 5. Soil texture weights on forest to pasture/family agriculture transition in small landholding area.

In the forest regeneration, an increasing relation with the TWI variable was observed. The value class 0 to 5 presented the weights -0.1 in 2004-2007, 1.2 in 2007-2010 and 1.4 in 2010-2013.

\section{DISCUSSION}

Considering the relationships between the distribution of natural resources and the occurrence of land use transitions, some hypotheses can be made about the mechanisms that act in the organization of the spatial patterns.

\section{A. Area of mechanized agriculture}

Regarding forest-pasture transition, the sand texture presented an increasing trend in weight in the analyzed period. In the study area, the sand texture occurs in the bottom of the valleys, characterized by the proximity to the superficial water resources and the presence of extensive livestock that depends on this resource for cattle watering. This progressive trend of deforestation for cattle farming in the valleys can be explained by the water access in the extensive livestock systems dominating the Amazonian agricultural frontier.

It is recognized that most of the deforested areas in Amazonia return to stages of forest succession [16]. Relatively rapid forest regeneration in the Amazon is often related to biophysical constraints (such as low soil fertility) and social obstacles that limit management options [17]. Between 2004 and 2013, about $994 \mathrm{~km}^{2}$ of forest had been transformed into pasture in Paragominas, while $716 \mathrm{~km}^{2}$ were in regeneration, which shows these cyclical dynamics of deforestation and regeneration, creating a landscape of productive pasture, degraded pasture and secundary forest.
Forest regeneration, as discussed above, is part of the cyclical dynamics of deforestation-regeneration characteristic of the extensive livestock system in the study area. However, part of the forest regeneration in the area with concentration of mechanized agriculture and large properties presented a spatial relationship with the TWI variable: class $0-5$ presented an increasing weight for this transition, especially after 2007. The low values of TWI are concentrated in the sloping areas. This condition leads to the hypothesis that this increase in the importance of slopes for regeneration may be related to the process of expansion of mechanized pasture management.

In the transition from pasture to mechanized agriculture the most important spatial variable was soil texture. It was observed that there is a predominance of this transition over the clayey soil (Belterra clay). This soil type is related to the topography, occurring on the top of the plateaux. The preference for the expansion of mechanized agriculture on the clayey soils is due to their higher fertility and the favorable topography [7] that allow cost reduction of grain production on a large scale. Approximately $477 \mathrm{~km}^{2}$ of pastures were transformed in agriculture between 2004 and 2013, mainly in the plateaux areas. It is noteworthy that it is in the plateaux that the greater proportion of forests of the county remains.

As of 2007, the restriction of deforestation by government and production chains control has limited deforestation and may have encouraged the expansion of crops over preexisting pastures. In 2004, the pasture on the plateaux covered 797.2 $\mathrm{km}^{2}$, and was reduced to $581 \mathrm{~km}^{2}$ in 2013 , a loss possibly linked to the expansion of agriculture.

\section{B. Smallholding areas}

In the areas occuped by smallholders, the relationship between the dynamics of land use and natural resources is different. It is recognized that in the areas of initial colonization, the natural resources present a lower weight in the transformations of land use [6], because factors such as the socioeconomic situation, the limitation of financial resources and choice of management frequently overlap natural factors.

However, the relationships observed in the smallholding areas of Paragominas present some aspects related to the distribution of natural resources. At first, most settlements are in the bottom of the valleys due to the proximity to the water resources (on the plateaux the permanent stream network is scarce). This phenomenon is also observed for other parts of Paragominas, where most of the initial deforestation was done at the bottom of the valleys [18] due to cattle access to water. Although sandy soils in the valleys are poor, this was not a strong constraint for forage production [7].

At the beginning of the observed period, part of the valleys had already been deforested, giving rise to crop family production and small livestock farming, while most of the plateaux had forest cover. Deforestation in this area showed a relationship with the class of mottled clay, which is distributed mainly on the slopes of the plateaus and is also a transition area between more open areas and more forested areas. However, it is also observed that the weight of this texture decreased progressively during the analyzed period, indicating 
the reduction of the contribution of this soil class in the spatial distribution of deforestation.

While deforestation on the slopes has been progressively reduced, regeneration progressively increases in this portion of the landscape. Regeneration is related to the class 0-5 of TWI, with weights that increase throughout the analyzed period. As already discussed, areas with low TWI values are related to the greater slopes in the edges of the plateaux. Indeed, the edges of the plateaux in the areas of family agriculture also present a cyclical transformation dynamic, with areas being deforested and others being left for regeneration.

This behavior may be related to the limitation of the resources and management alternatives of clearing areas in the context of small properties [19]. After 3 to 5 years, many Amazonian pastures present decreases in productivity due to factors such as soil fertility loss, overgrazing and invasive plant growth [20]. The cost of pasture reform depends on several factors, such as the relative prices of machinery, livestock and land [21], which can often make pasture management inviable and generates an abandonment of the area.

\section{CONCLUSION}

The results confirm the hypothesis that during the period between 2004 and 2013 the natural resources have relevance in the land use change in the Paragominas county, especially with respect to the texture of the soil, that is distributed in function of the topography and the hydrographic network. From 1960s to 2000, the forest was cleared for extensive cattle farming. Since 2000s, a new land use dynamic is observed based on mechanization and crop as soybeans and environmental law and control enforcement. The initial livestock expansion was through the bottom of the valleys, visible until now with most of the open areas of the county. More recently, the valorization of clayey plateaux for mechanized agriculture and the restriction of deforestation has caused their expansion on the preceding pastures. In the bottom of the sandy valleys, extensive cattle ranching remains prevailing with intense dynamics of deforestation and regeneration cycles. In areas of small landholders, a dynamic of deforestation and regeneration predominates on the slopes of the plateaux, reflecting the expansion of activities from the valleys towards the plateaux.

\section{ACKNOWLEDGMENT}

The research was conducted with the financial support of the French Agence Nationale de la Recherche (ECOTERA project, ANR-13-AGRO-0003), of the Brazilian National Council of Technological and Scientific Development (CNPq), and of the Cirad.

\section{REFERENCES}

[1] INPE - Instituto Nacional de Pesquisas Espaciais, "PRODES - Projeto de monitoramento do desflorestamento da Amazônia", 2009. $<$ http://www.obt.inpe.br/prodes/index.php >.
[2] S. Margulis, "Causas do desmatamento da Amazônia brasileira", vol. 80. 2003.

[3] E. Y. Arima, P. Richards, R. Walker, and M. M. Caldas, "Statistical confirmation of indirect land use change in the Brazilian Amazon," Environ. Res. Lett., vol. 6, no. 2, p. 24010, 2011.

[4] D. Nepstad et al., "Slowing Amazon deforestation through public policy and interventions in beef and soy supply chains.," Science, vol. 344, no. 6188, pp. 1118-23, 2014.

[5] D. Arvor, M. Meirelles, V. Dubreuil, A. Bégué, and Y. E. Shimabukuro, "Analyzing the agricultural transition in Mato Grosso, Brazil, using satellite-derived indices," Appl. Geogr., vol. 32, no. 2, pp. 702-713, 2012

[6] M. Dosso et al. "Agriculture ou élevage ? Rôle des couvertures pédologiques dans la différenciation et la transformation de systèmes agraires pionniers au Brésil," Cah. Agric., vol. 14, no. 1, pp. 76-84, 2005.

[7] M.-G. Piketty et al., "Multi-level governance of land use changes in the Brazilian Amazon: Lessons from Paragominas, State of Pará," Forests, vol. 6, no. 5, pp. 1516-1536, 2015.

[8] C. Kummerow, W. Barnes, T. Kozu, J. Shiue, and J. Simpson, "The tropical rainfall Measuring Mission (TRMM) Sensor Package". J. Atmospheric Ocean. Technol. 15, 809-817. 1998.

[9] F. Perrier, "Caractérisation et cartographie de l'éco-efficience des pâturages amazoniens à l'aide d'images MODIS," Université du Maine. pp. 1-82, 2014.

[10] F. Laurent, R. Poccard-chapuis, S. Plassin, and G. P. Martinez, "Soil texture mapping derived from topography in the North-eastern Amazonia," Journal of Maps, vol. 5647, no. 1, pp. 1-20, 2017

[11] K. J. Beven and M. J. Kirkby, "Physically based, variable contibution area model of basin hydrology," Hydrological Sciences Bulletin, vol. 24, no. 1. pp. 43-69, 1979

[12] M. M. Valeriano and D. F. Rossetti, "Topodata: Brazilian full coverage refinement of SRTM data," Appl. Geogr., vol. 32, no. 2, pp. 300-309, 2012

[13] K. Goodacre, G. F. Bonham-Carter, F. P. Agterberg, and D. F. Wright, "A statistical analysis of the spatial association of seismicity with drainage patterns and magnetic anomalies in western Quebec," Tectonophysics, vol. 217, no. 3-4, pp. 285-305, 1993.

[14] S. Soares-Filho, G. Coutinho Cerqueira, and C. Lopes Pennachin, "DINAMICA - A stochastic cellular automata model designed to simulate the landscape dynamics in an Amazonian colonization frontier," Ecol. Modell., vol. 154, no. 3, pp. 217-235, 2002.

[15] L.D. Kemp, G.F. Bonham-Carter, G.L. Raines, “Arc-WofE: Arcview extension for weights of evidence mapping" 1999. http://www.ige.unicamp.br/wofe.

[16] P. M. Fearnside, "Amazonian deforestation and global warming: carbon stocks in vegetation replacing Brazil's Amazon forest". Forest Ecology and Management, 80: 21-34. 1996.

[17] G. S. Perz and D. L. Skole, "Secondary forest expansion in the Braziliam Amazon and the refinement of forest transition theory", Society e Natural Resources, Vol. 16, no. 4, 2003.

[18] O. T. Almeida and C. Uhl, Planejamento do uso do solo do município de Paragominas utilizando dados econômicos e ecológicos. IMAZON (Ed.), Belém, Brazil, 1998.

[19] N. Cialdella, et al., Do political changes aimed at reducing Amazonian deforestation contribute to ecological intensification? Cahiers Agricultures, 24: 246-254, 2015.

[20] C. R. Townsend, N. L. Costa, and R. G. A. Pereira, “Aspectos econômicos da recuperação de pastagens na Amazônia brasileira” pp. 27-50, 2010 .

[21] E. Arima and C. Uhl, "Pecuária na Amazônia Oriental: desempenho atual e perspectivas futuras" vol. Série Amaz, p. 40, 1996. 